\title{
Family Caregivers' Involvement in Caring with Cancer and their Quality of Life
}

\author{
Sevcan Toptas Kilic ${ }^{1 *}$, Fatma $\mathbf{O z}^{2}$
}

\begin{abstract}
Background: Cancer is a chronic disease and a major health problem. It affects both patients and their family caregivers multidimensionally. The family caregivers may be affected by not only the disease process but also hospital policies, economic difficulties, accessibility and communication of health care service and can be in need of help. This process may affect their quality of life. However, there have not been enough studies on quality of life of family caregivers of patients with cancer in Turkish culture. Therefore, this study aimed to evaluate the quality of life of family caregivers of patients with cancer in Turkey. Objectives: The purpose of study was to evaluate the quality of life of family caregivers with cancer patients in Turkey. Methods: Participants consist of the family caregivers who volunteered to take part in this descriptive study from 11 hospitals $(n=378)$ which has a daily chemotherapy units and located within the boundaries of Ankara, Turkey. 'Sociodemographic Characteristic Form' and 'Quality of Life Scale-Family Version were used as data collection tool. The Kruskal-Wallis and Mann-Whitney U, tests were used for data analysis. Resultes:It is found that there are statistically significant difference among the factors of gender, employment status, income level, and whether caregivers reside with their patients. Family caregivers' quality of life is negatively affected during the caregiving process $(\mathrm{p}<0.05)$. Conclusion: The results indicate that family caregivers' quality of life are negatively affected to care process. The results of this research are important as they highlight the need to also consider family caregivers' quality of life when caring for patients, and study highlight possible areas in which support can be provided for family caregivers of cancer patients in Turkey.
\end{abstract}

Keywords: Oncology- caregiver- quality of life

Asian Pac J Cancer Prev, 20 (6), 1735-1741

\section{Introduction}

Cancer is a chronic disease and a major health problem (Tamayo et al., 2010). It continues to be among the most feared life-threatening diseases despite significant advances in diagnosis and treatment with technological advancement (Güllü and Zengin, 2009). It is the second most common disease in many countries, including Turkey, not only threatening death but also affecting the structure and function of families (Uğur and Fadıloğlu, 2012). It affects both patients and their family caregivers multidimensionally. The family caregivers may be affected by not only the disease process but also hospital policies, economic difficulties, and accessibility and communication of health care service and can be in need of help (Given et al., 2012; Ferrell et al., 2013; Chen et al., 2018). Family caregivers (FCs) of patients with cancer may experience a host of problems, such as anger, hopeless, alone, fear, anxiety, burden, and depression (Chang et al.,2013; Stajduhar, 2013; Effendy et al., 2014). Cancer is no longer considered an acute disease as the survival rates have increased due to improvements in cancer diagnosis, treatment, and care. During cancer treatment, family caregivers play an important role (Kim and Given, 2008). Family caregivers are those who provide uncompensated care in the home and who have a pre-existing relationship (either through friendship or kinship) to the person for whom care is being provided. They assist patients in addressing physical, emotional, and medical problems (Northouse et al., 2010; Mosher et al., 2013). This care may be in any of the quality-of-life (QOL) domains including physical, social, psychological, and spiritual care. Like cancer patients, FCs themselves have diverse needs and health concerns. Caregiver needs and access to resources vary on the basis of many factors, including gender, age, culture, education, economics, and geographic setting (Tamayo et al., 2010). Studies indicate that that, when patient distress increases and symptoms can no longer be controlled, family caregivers experience burden, depression, social isolation, difficulty in concentration, and anxious tendencies (Skarstein et al., 2000).

In addition, family caregivers develop physical problems such as indigestion, changes in appetite, 
irregular eating habits, headaches, chronic fatigue, weight gain or loss, or muscle pain, resulting in poor quality of life (QoL) (Kitrungrote and Cohen, 2006; Çivici et al., 2011; Turkoğlu and Kilic, 2012; Wadhwa et al., 2013;Kim et al., 2015). Research clearly indicates that the problems experienced by patients with cancer also negatively affect their caregivers. This may cause their QoL to decrease (Park et al., 2013; Sun Young et al., 2015). Therefore, efforts should be made to reduce the burden on family caregivers and to decrease their emotional problems to allow them to provide optimal support and effective long-term care (Pinkert et al., 2013)

As a result, studies have documented that family caregivers feel they are not adequately supported by healthcare professionals. Nurses, as health professionals, can have a positive impact on the well-being of caregivers. Oncology nurses are important members of the cancer team and remain key to the success of patients and family caregivers in providing high-quality, person-centered care. Nurses evaluate QoL of family caregivers and value the opportunities to use a standardized, consistent approach that enables caregivers to report distress (Ferrel and Grant, 2005). However, there have not been enough studies on QoL of family caregivers of patients with cancer in Turkish culture. Therefore, this study aimed to evaluate the QoL of family caregivers of patients with cancer in Turkey. After evaluating their QoL, it also aimed to reflect the results in the nursing care of oncology nurses. The following questions guided this study:

1. What are family caregivers' quality of life?

2. Which sociodemographic family caregivers' descriptive features are associated with these Quality of life?

3. Do family caregivers' views on experiences about care with cancer patient?

\section{Materials and Methods}

\section{Study Design and Sample}

This study was conducted using a descriptive method. Units daily patients list were skimmed through for eligibility patients who came with a caregivers were approached. The caregivers of this patients were invited to participate in study if they were aging 18 years and older, literate, and being primary caregiver of the cancer patient. The participants were family caregivers who accompanied patients with cancer when the latter received daytime treatment at 11 chemotherapy units in Ankara. The required sample size was calculated using the "finite population sampling" formula, and the total number was calculated to be 378 family caregivers. The study sample consisted of family caregivers who volunteered to participate in our study. The response rate could not be calculated because the sample size was calculated in advance. The study was performed in other clinics until the target number of sample was reached. Participants were interviewed face to face with caregivers in the waiting room. The duration of data collection was approximately $30 \mathrm{~min}$ per individual.

\section{Data Collection}

The data were collected through face-to-face interviews by researchers in hospital daily chemotherapy units. Researchers were available at the relevant unit to answer possible questions during this period.

\section{The sociodemographic characteristic}

The family caregiver sociodemographic characteristic includes age, gender, marital status, education level, work status, and illness treatment characteristics (e.g., diagnosis, duration of caregiving, relationship with patient, type of cancer, chemotherapy cycles, and information about caregivers). There is also 1 open-ended question whether they have experienced affected by care process.

Quality of Life Scale-Family Version (QoL-FV). The scale developed by Ferrell and Grant. (Ferrel and Grant, 2005). In this study the Turkish version was used. The test-retest reliability coefficient was found $(r=.86)$, and Cronbach's alpha coefficient for internal consistency was $=.90$. The QoL-FV is composed of 4 subscales: Psychological and Spiritual Health Status (1, 2, 3, 4, 5, $6,7,8,9,10,11)$, Physical Health Status $(12,13,14,15$, $16,17,18,19,20)$, Approach to Diagnosis Status $(21,22$, 23, 24, 25, 26, 27), and Support and Economic Response Status $(28,29,30,31)$. Some questions $(1,12-15,17-28$, $30,31)$ were reversely encoded. The scale is expressed by collecting the response scores regarding the items of relevant size of total and subscale mean scores and dividing the number of items/questions. The scale is interpreted through total and subscale scores, and a high score indicates high QoL (Okçin and Karadakovan, 2012).

\section{Ethical Approval}

After written permission was received from the "The University Non-Interventional Clinical Research Ethics" (LUT 12/48 reference number) and hospitals, family caregivers were informed about the study. After receiving written consent from the volunteering family caregivers, questionnaires were conducted until the target sample was reached.

\section{Analysis}

The data were analyzed using the SPSS 20.0. Frequencies and percentages were used to determine family caregivers' descriptive characteristics. The sampling did not show a normal distribution. Therefore, non-parametric tests were used for analysis. Distinctive differences in QoL were assessed using the Mann-Whitney U test for comparisons with two categories, and Kruskal-Wallis one-way analysis of variance was used for comparisons of more than two categories. The Bonferroni correction was used to determine the origin of the differences. Differences between groups were considered significant at a level of $\mathrm{p}<0.05$.

\section{Results}

\section{Caregiver Characteristics}

A description of the family caregivers is shown in Table 1. A total of 378 family caregivers were recruited and interviewed. In this study, caregivers were predominantly 
Table 1. Descriptive Characteristics (N=378).

\begin{tabular}{|c|c|c|}
\hline Variables & Frequency (n) & $\%$ \\
\hline \multicolumn{3}{|l|}{ Gender } \\
\hline Female & 243 & 64.3 \\
\hline Male & 135 & 35.7 \\
\hline \multicolumn{3}{|l|}{ Age } \\
\hline $20-30$ & 69 & 18.3 \\
\hline $31-50$ & 192 & 50.8 \\
\hline $51+$ & 117 & 31 \\
\hline \multicolumn{3}{|l|}{ Marital status } \\
\hline Single & 93 & 24.6 \\
\hline Married & 285 & 75.4 \\
\hline \multicolumn{3}{|l|}{ Education status } \\
\hline Primary school & 112 & 29.6 \\
\hline Secondary school & 127 & 33.6 \\
\hline High school & 89 & 23.5 \\
\hline Üniversity & 43 & 11.4 \\
\hline Graduate & 7 & 1.9 \\
\hline \multicolumn{3}{|l|}{ Employment status } \\
\hline Employed & 145 & 38.4 \\
\hline Unemployed & 183 & 48.4 \\
\hline Retired & 50 & 13.2 \\
\hline \multicolumn{3}{|l|}{ Income status } \\
\hline Least income expense & 131 & 34.7 \\
\hline Equal to the revenue expenditure & 193 & 51.1 \\
\hline Revenue over expenses & 54 & 14.3 \\
\hline \multicolumn{3}{|l|}{ Children } \\
\hline With children & 276 & 73.2 \\
\hline Without children & 101 & 26.8 \\
\hline \multicolumn{3}{|l|}{ Patient Relationship } \\
\hline Spouse & 110 & 29.1 \\
\hline Mother & 92 & 24.3 \\
\hline Father & 58 & 15.3 \\
\hline Brother/sister & 46 & 12.2 \\
\hline Son/daughter & 7 & 1.9 \\
\hline Others & 65 & 17.2 \\
\hline \multicolumn{3}{|l|}{ Duration of caregiving (hour/day) } \\
\hline $1-6$ & 203 & 53.7 \\
\hline $7-12$ & 57 & 15.1 \\
\hline $13-18$ & 7 & 1.9 \\
\hline $19-24$ & 111 & 29.4 \\
\hline \multicolumn{3}{|l|}{ Care support from other family members } \\
\hline Present & 194 & 51.3 \\
\hline Absent & 183 & 48.4 \\
\hline \multicolumn{3}{|l|}{ Living in the same household status } \\
\hline Yes & 217 & 57.4 \\
\hline No & 161 & 42.6 \\
\hline
\end{tabular}

female $(64.3 \%, \mathrm{n}=243) ; 75.4 \%$ were married. The majority of participants ranged in age from 31 to 50 years $(50.8 \%, \mathrm{n}=192)$; the majority were primary $(29.6 \%, \mathrm{n}=$ $112)$ and secondary school $(33.6 \%, \mathrm{n}=127)$ graduates, $48.4 \%$ were unemployed, and the income level of $34.7 \%$
Table 2. Caregivers are Affected by the Disease Process

\begin{tabular}{lcc}
\hline Affected Situation & Frequency $(\mathrm{n})$ & Percent $\%$ \\
\hline The caregiver's own life being affected by the disease process \\
Not affected & 45 & 11.90 \\
Negative affected & 306 & 81 \\
Affected & 27 & 7.10 \\
The caregiver's family life & & \\
Not affected & 57 & 15.10 \\
Positive affected & 84 & 24.20 \\
Negative affected & 208 & 55.1 \\
No answer & 29 & 7.70 \\
The caregiver's job life & & \\
Not affected & 152 & 40.20 \\
Negative affected & 182 & 48.10 \\
No answer & 44 & 11.20 \\
The caregiver's social life & & \\
Not affected & 132 & 29.60 \\
Negative affected & 219 & 63.20 \\
No answer & 27 & 7.20 \\
Total & 378 & 100.00 \\
\hline
\end{tabular}

of the participants could be classified as low. Regarding the kinship of the family caregivers, one-third $(29.1 \%, \mathrm{n}$ $=110$ ) were participants' spouses. More than half $(53.7 \%$, $\mathrm{n}=203$ ) had been caring for the patient for 1-6 hours, one-third $(29.4 \%, \mathrm{n}=111)$ all day, and more than half $(57.4 \%, \mathrm{n}=217)$ shared a residence with patients and did not get any support from others during caregiving $(48.4 \%, \mathrm{n}=183)$.

\section{Responses from Family Caregivers Affected by the Caregiving Process}

Regarding the family caregivers' responses to disease-related processes, $81 \%$ were negatively affected, and only $11.9 \%$ were not affected. When examining how caregivers' families were affected by the caregiving process, more than half $(55.1 \%)$ were affected negatively, and $24.2 \%$ were affected positively. While the working lives of almost half of the caregivers $(48.1 \%)$ were adversely affected, $40.2 \%$ of the caregivers reported not being affected. Some of the caregivers explained that the lack of effect was because they had their own businesses or were retired. Most caregivers (63.2\%) reported that their social lives were negatively affected whereas $29.6 \%$ said that they were not affected (shown in Table 2).

Table 3. Family Caregivers "QoL-Family Version" Mean Scores in Four Domains

\begin{tabular}{lc}
\hline Quality Of Life Scale-Family Version & Median (min-max) \\
\hline Psychological and Spiritüel Well Being & $5.45(0-10)$ \\
Physical Well Being & $5.44(0.22-10)$ \\
Diagnostic Approach to Status & $2.71(0-9.43)$ \\
Support and Economic Impact Status & $4.75(0-10)$ \\
Total & $4.83(0.87-8.71)$ \\
\hline
\end{tabular}

Asian Pacific Journal of Cancer Prevention, Vol 201737 
Table 4. Comparison of Mean Scores of the Four Domains Related to Description of Family Caregivers (N=378).

\begin{tabular}{|c|c|c|c|c|c|c|}
\hline \multicolumn{2}{|c|}{ Descriptives } & \multicolumn{5}{|c|}{ Quality Of Life Scale-Family Version } \\
\hline & & $\begin{array}{l}\text { Total Scale Score } \\
\text { Median (min-max) }\end{array}$ & $\begin{array}{c}\text { Psychological and } \\
\text { Spiritüel Well Being } \\
\text { Median (min-max) }\end{array}$ & $\begin{array}{c}\text { Physical } \\
\text { Well Being } \\
\text { Median (min-max) }\end{array}$ & $\begin{array}{c}\text { Diagnostic } \\
\text { Approach to Status } \\
\text { Median (min-max) }\end{array}$ & $\begin{array}{c}\text { Support and } \\
\text { Economic Impact Status } \\
\text { Median (min-max) }\end{array}$ \\
\hline \multirow{3}{*}{$\begin{array}{l}\overrightarrow{\tilde{v}} \\
\stackrel{\bar{E}}{0}\end{array}$} & Female $(\mathrm{n}=243)$ & $4.55(0.87-8.71)$ & $5(0-10)$ & $5(0.22-10)$ & $2.43(0-9.43)$ & $4.75(0-10)$ \\
\hline & Male (n=135) & $5.19(2-8.58)$ & $5.82(1.55-9.82)$ & $6(1.44-10)$ & $3.29(0-9)$ & $4.75(0-9.5)$ \\
\hline & Statistical analysis* & $\begin{array}{c}\mathrm{U}=20.122 \\
\mathrm{p}=0.000\end{array}$ & $\begin{array}{c}\mathrm{U}=20.340 \\
\mathrm{p}=0.000\end{array}$ & $\begin{array}{c}\mathrm{U}=19.061 \\
\mathrm{p}=0.009\end{array}$ & $\begin{array}{c}\mathrm{U}=20.527 \\
\mathrm{p}=0.000\end{array}$ & $\begin{array}{c}\mathrm{U}=16.086 \\
\mathrm{p}=0.756\end{array}$ \\
\hline \multicolumn{7}{|c|}{ *Mann Whitney U Test is used } \\
\hline \multicolumn{7}{|c|}{ *Kruskal-Wallis Varyans Analyz is used.. } \\
\hline \multirow{6}{*}{ 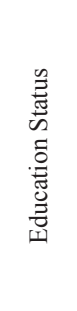 } & Primary school a $(\mathrm{n}=112)$ & $4.71(1.13-8.68)$ & $4.91(0.82-9.55)$ & $5.44(0.67-9.89)$ & $2.86(0-9)$ & $4.13(0-10)$ \\
\hline & Secondary school ${ }^{b}(n=127)$ & $4.74(0.87-8.19)$ & $5.36(1.64-8.45)$ & $4.67(0.22-9.44)$ & $3(0-7.86)$ & $4.25(0-9.25)$ \\
\hline & High school ${ }^{\mathrm{c}}(\mathrm{n}=89)$ & $4.84(1.19-8.71)$ & $5.27(0-9.64)$ & $5(1.22-10)$ & $2.71(0-9.43)$ & $4.75(0-8.75)$ \\
\hline & Üniversity ${ }^{\mathrm{d}}(\mathrm{n}=43)$ & $4.97(1.13-8.71)$ & $5.73(0.82-10)$ & $5.78(1.33-10)$ & $2.43(0-8)$ & $5.25(0.5-9.25)$ \\
\hline & Graduate ${ }^{e}(\mathrm{n}=7)$ & $5.42(4.06-7.45)$ & $5.45(4.82-8.91)$ & $6(3.22-8.89)$ & $2.86(1.86-6.14)$ & $5.50(3.5-9.25)$ \\
\hline & Statistical analysis* & $\begin{array}{c}\mathrm{KW}=7.424 \\
\mathrm{p}=0.115\end{array}$ & $\begin{array}{c}\mathrm{KW}=17.043 \\
\mathrm{p}=0.002\end{array}$ & $\begin{array}{c}\mathrm{KW}=8.342 \\
\mathrm{p}=0.080\end{array}$ & $\begin{array}{c}\mathrm{KW}=4.811 \\
\mathrm{p}=0.307\end{array}$ & $\mathrm{KW}=8.906 \mathrm{p}=0.063$ \\
\hline \multirow{5}{*}{ 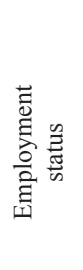 } & \multicolumn{6}{|c|}{ *Kruskal-Wallis Varyans Analyz is used. Psychological and Spiritüel Well Being: a-d } \\
\hline & Employed ${ }^{a}(n=145)$ & $4.97(0.87-8.58)$ & $5.55(082-9.64)$ & $5.89(0.22-10)$ & $2.71(0-9)$ & $4.75(0-9.25)$ \\
\hline & Unemployed ${ }^{\mathrm{b}}(\mathrm{n}=185)$ & $4.52(1.13-8.71)$ & $4.91(0-10)$ & $5(0.67-9.89)$ & $2.57(0-9)$ & $4.50(0-10)$ \\
\hline & Retiredc $(\mathrm{n}=50)$ & $5.26(2-8.71)$ & $6.18(1.55-9.91)$ & $5.50(1.67-10)$ & $3.36(0-9.43)$ & $5.75(0-9.25)$ \\
\hline & Statistical analysis* & $\begin{array}{c}\mathrm{KW}=10.375 \\
\mathrm{p}=0.006\end{array}$ & $\begin{array}{c}\mathrm{KW}=15.919 \\
\mathrm{p}=0.000\end{array}$ & $\begin{array}{c}\mathrm{KW}=7.914 \\
\mathrm{p}=0.019\end{array}$ & $\begin{array}{c}\mathrm{KW}=2.848 \\
\mathrm{p}=0.241\end{array}$ & $\mathrm{KW}=5.832 \mathrm{p}=0.054$ \\
\hline & *Kruskal-Wallis Varyans $\mathrm{Ar}$ & lyz is used. Total sca & b-a, b-c Psychologic & and Spiritüel Well B & eing: b-a, b-c, Physica & 1 Well Being :b-a \\
\hline \multirow{4}{*}{ 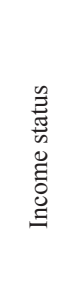 } & $\begin{array}{l}\text { least income expense } \\
{ }^{\mathrm{a}}(\mathrm{n}=131)\end{array}$ & $4.19(0.87-8.71)$ & $4.91(0.82-9.45)$ & $5(0.22-9.44)$ & $2.71(0-9.43)$ & $3.75(0-9.5)$ \\
\hline & $\begin{array}{l}\text { equal to the revenue } \\
\text { expenditure }^{b}(n=193)\end{array}$ & $4.90(1.13-8.58)$ & $5.55(0-9.91)$ & $5.56(0.67-10)$ & $2.57(0-9)$ & $5(0-10)$ \\
\hline & $\begin{array}{l}\text { Revenue over expenses } \\
{ }^{\circ}(\mathrm{n}=54)\end{array}$ & $5.56(1.13-8.71)$ & $6.50(0.82-10)$ & $6.94(1.33-9.89)$ & $3.43(0-8.43)$ & $5.50(1.75-8.50)$ \\
\hline & Statistical analysis* & $\begin{array}{c}\mathrm{KW}=22.244 \\
\mathrm{p}=0.000\end{array}$ & $\begin{array}{c}\mathrm{KW}=25.719 \\
\mathrm{p}=0.000\end{array}$ & $\begin{array}{c}\mathrm{KW}=15.998 \\
\mathrm{p}=0.000\end{array}$ & $\begin{aligned} \mathrm{KW} & =5.058 \\
\mathrm{p} & =0.080\end{aligned}$ & $\mathrm{KW}=25.895 \mathrm{p}=0.000$ \\
\hline
\end{tabular}

*Kruskal-Wallis Varyans Analyz is used. Total scale: a-b, a-c, b-c, Psychological and Spiritüel Well Being: a-b, a-c, b-c Physical Well Being : c-a, c-b, Support and Economic Impact Status : a-b, a-c

\begin{tabular}{|c|c|c|c|c|c|c|}
\hline \multirow{5}{*}{ 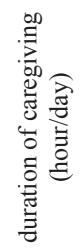 } & $1-6^{a}(n=203)$ & $5.35(0.87-8.71)$ & $5.73(0.73-10)$ & $6.56(0.22-10)$ & $3(0-9)$ & $5.25(0-10)$ \\
\hline & $7-12^{b}(n=57)$ & $4.10(1.65-8.71)$ & $5(0.82-9.45)$ & $4.78(0.89-8.89)$ & $1.71(0-9.43)$ & $4(0.5-8.5)$ \\
\hline & $13-18 s^{c}(n=7)$ & $4.94(2.35-5.06)$ & $4.91(3.73-7.73)$ & $5.44(1.33-7.89)$ & $1.86(0.57-4.86)$ & $4(2.5-4.75)$ \\
\hline & $19-24^{\mathrm{d}}(\mathrm{n}=111)$ & $4.03(1.13-8.68)$ & $4.91(0-9.82)$ & $4.33(0.67-9.89)$ & $2.71(8.57)$ & $4(0-9.5)$ \\
\hline & Statistical analysis* & $\begin{array}{c}\mathrm{KW}=35.607 \\
\mathrm{p}=0.000\end{array}$ & $\begin{array}{c}\mathrm{KW}=17.915 \\
\mathrm{p}=0.000\end{array}$ & $\begin{array}{c}\mathrm{KW}=51.939 \\
\mathrm{p}=0.000\end{array}$ & $\begin{array}{c}\mathrm{KW}=8.806 \\
\mathrm{p}=0.032\end{array}$ & $\mathrm{KW}=24.129 \mathrm{p}=0.000$ \\
\hline
\end{tabular}

Kruskal-Wallis Varyans Analyz is used. Total scale: a-b, a-d, Psychological and Spiritüel Well Being: a-d, Physical Well Being:a-b, a-d, Diagnostic

\begin{tabular}{|c|c|c|c|c|c|}
\hline Spousea $(n=110)$ & $4.18(113-8.68)$ & $5(0.82-9.82)$ & $4.50(0.67-9.89)$ & $2.79(0-8.57)$ & $4.13(0-9.25)$ \\
\hline Motherb $(n=92)$ & $4.65(0.87-8.58)$ & $5.18(0-9.55)$ & $5.44(0.22-10)$ & $2.14(0-9)$ & $4.50(0-9)$ \\
\hline Fatherc $(\mathrm{n}=58)$ & $4.87(2.35-7.97)$ & $5.41(1.45-9.64)$ & $5.56(1.33-9)$ & $2.71(0-6.86)$ & $4.25(0.5-9.5)$ \\
\hline Brother/sisterd $(n=46)$ & $5.02(1.68-8.71)$ & $5.77(1.64-9.91)$ & $6(0.89-10)$ & $2.93(0-9.43)$ & $5.50(1.25-10)$ \\
\hline Daughter/sone $(n=7)$ & $3.58(2.35-6.97)$ & $3.91(2.91-6.91)$ & $4.33(3.67-7)$ & $2.43(0.14-6.71)$ & $3.25(0-7.5)$ \\
\hline Others $(\mathrm{n}=65)$ & $5.77(1.55-8.71)$ & $6.27(0.73-10)$ & $7.11(2.33-9.89)$ & $3.29(0-7.86)$ & $5.75(0.25-9.5)$ \\
\hline Statistical analysis* & $\begin{array}{c}\mathrm{KW}=29.889 \\
\mathrm{p}=0.000\end{array}$ & $\begin{array}{c}\mathrm{KW}=19.513 \\
\mathrm{p}=0.002\end{array}$ & $\begin{array}{c}\mathrm{KW}=34.147 \\
\mathrm{p}=0.000\end{array}$ & $\begin{array}{c}\mathrm{KW}=10.626 \\
\mathrm{p}=0.059\end{array}$ & $\mathrm{KW}=26.411 \mathrm{p}=0.000$ \\
\hline
\end{tabular}

Kruskal-Wallis Varyans Analyz is used. Total scale: a-f, b-f, c-f, Psychological and Spiritüel Well Being: c-f, a-f, Physical Well Being: a-f, b-f, Support and Economic Impact Status: b-f, a-f, c-f, a-d

\section{QOL-FV Family Caregivers $(N=378)$}

The family caregivers' median scores on the five domains are shown in Table 3 . The caregivers' median total QOL-FV score was $4.83(\max =8.71, \min =0.87)$. The median subscale scores were as follows: 5.45 ( $\max =$ $10.0, \min =0.00$ ) for Psychological and Spiritual Health, $5.44(\max =10.0, \min =0.22)$ for Physical Health, 2.71 $(\max =9: 43, \min =0.00)$ for Approach to Diagnosis, and $4.75(\max =10.0, \min =0.00)$ for Support and Economic Response. A comparison of the min-max scores suggested that the Psychological and Spiritual Health subscale was moderate and that the Approach to Diagnosis, Support 
and Economic Response, and total QoL scores were below average.

As shown in Table 4 there were statistically significant differences between some mean participants scores on account of some variables in the samples. There were no significant differences between caregivers' ages, marital statuses, patients' cancer types, and QoL scores. There were statistically significant differences in terms of caregivers' gender, education status, employment status, financial status, relationship with patient, and whether caregivers resided with their patients $(p=0.000$, $p<0.05$ ) (Table 4). Female caregivers were found to have lower quality of life than male caregivers. The quality of life scores of the students with primary school education level were lower than those with university education level in "Psychological and Spiritual Health" in subscale. The quality of life scores of "Psychological and Spiritual Health" and "Physical Health" were found to be lower compared to others.

\section{Discussion}

In Turkey, the family plays an important role in patient care. It is a tradition and considered an obligation to take care of a family member who is sick at home as well as during medical care (Hacioğlu et al., 2010; Sercekus et al., 2014). Firstly, this study revealed that QoL scores were lower among female than among male caregivers. This may occur because of the high responsibility of women in society. The caregiving role is considered multi-dimensional and includes the patient, children, housework, shopping, maintenance of social relationships, and children's education. Society traditionally regards women as playing a role in all these areas in Turkey. Therefore, female caregivers are expected to take on these roles and are also not used to accepting assistance or sharing responsibility. Eventually, this leads to an increased sense of burden and decreased QoL (Scherbring, 2002; Awadalla et al., 2007; Alptekin, 2010). Secondly, our study revealed that there are statistically significant differences among education levels according to mean QoL-FV score. This could be due to increased financial and social opportunities as well as education levels themselves. Caregivers with higher educational attainment may have more knowledge and communication skills, may know more efficient stress management techniques, and may find it easier to cope with problems. Studies suggest that caregivers with lower educational levels are less efficient at meeting patients' treatment needs, and this could adversely affect their QoL (Gözüm and Akçay, 2005; Gaugler et al., 2005). Thirdly, we found that the QoL-FV scores were lower for unemployed caregivers than for employed or retired caregivers. When not working, caregivers cannot provide economically efficient care, and the lack of gainful employment can lead to a sense of worthlessness. Thus, poorer QoL might be expected among unemployed caregivers, even though this reduces the overall level of responsibility, enabling these caregivers to devote more time to patients. Gaugler et al., (2005) reported different findings from ours that employed caregivers reported feelings of inadequacy with regard to care provision due to their work obligations. This, in turn, increased depressive symptoms and reduced their QoL. Our findings are supported by several studies showing that caregivers with a monthly income less than their expenses obtained the least QoL (Yun et al., 2005; Longo et al., 2006) Next, our study revealed that the QoL of caregivers of patients who had been diagnosed a year or less earlier was lower compared to those who had been diagnosed more than five years earlier. Similarly, in the literature, some studies showed poor QoL among spouses caring for newly diagnosed patients (Neyt and Albrecht, 2006; Görgülü and Akdemir, 2010). Some studies have also indicated an increase in the QoL of both the patient and the caregiver following successful treatment, also indicating that caregivers maintained this process better and used social support more efficiently (Neyt and Albrecht, 2006; Osse et al., 2006; Yoo et al., 2008). Then, we also found that the mean QoL-FV scores were not statistically significant according to diagnosis. This may suggest that the type of cancer with which a patient is diagnosed was less important than the cancer diagnosis itself. This statement suggests that any type of cancer may result in negative feelings among family caregivers as a result of fear, anxiety, uncertainty, and death. Thus, the psychological QoL may be negatively affected.

Next, in our study, the mean QoL-FV scores for caregivers providing 1-6 hours were higher than for those for caregivers providing for longer periods. Some studies have reported that depression and anxiety levels, as well as the burden of caregiving, were closely associated with the caregiving duration during the week (Song et al., 2011; Ito and Tadaka, 2017). Moreover, the caregiving burden tended to decrease over time, though the perceived burden did not change after six months (Yoo et al., 2008). This suggested that caregivers prioritize their patients and neglect their own needs.

Then, in our study, a statistically significant difference in the total QoL-FV score was found with regard to employment status. Moreover, caregivers whose work was not affected by caregiving obtained significantly lower QoL scores, compared to those whose work was affected. Employed caregivers stated that they had to leave their jobs, retire, or close their workplaces even when they had not planned to do so (Çivici et al., 2011). Furthermore, Longo et al., (2006) conducted their study among 893 caregivers and reported that caregivers had to sell their assets, take out mortgages, or find additional work to meet their patients' healthcare needs. In contrast, some caregivers mentioned that the cancer-related processes positively affected their families, bringing them closer together and enabling them to engage with each other. This demonstrates that this process might not have a universally negative effect on families but may even strengthen family bonds.

Lastly, statistically significant differences were found in total QoL scores based on social life during caregiving. In another study, caregivers did not have the time and energy to meet their own needs, relax, engage in leisure activities, and visit their friends or relatives, and this exacerbated their difficulties (Osse et al., 2006; Uğur and Fadıloğlu, 2012). According to our study, it 
can be concluded that caregivers experienced a physical burden as a result of the change in roles, not having time to themselves, providing care almost all day, and poor work performance as well as an emotional burden based on their perception that caregiving was a liability. The burdens negatively affected the caregivers' QoL. A negatively affected QoL was considered a risk to the well-being and physical and mental health of caregivers (Song et al., 2011).

\section{Application}

The study's results show that care for patients with cancer by family caregivers can be challenging in multiple ways. In contrast, healthcare professionals must have QOL-FV focus in caring for patients with cancer who have family caregivers. Furthermore, they ought to work in an interdisciplinary fashion and provide both patients and family caregivers with adequate information and tools to handle their situation to promote QOL-FV and well-being. Having a QOL-FV perspective gives a variety of possibilities for health-promoting interventions. Such interventions may be related to practical coping, physical activity, and information and communication as well as social network support. The results also indicate that healthcare professionals and researchers should have a family-oriented focus and develop interventions targeted toward the entire family.

In conclusion, in our study, the QoL of family caregivers was significantly low. It was even lower for female caregivers, caregivers with lower socio-economic status and lower education levels, unemployed caregivers, those caring for recently diagnosed patients, those living with patients, those providing care for longer periods, those with immediate family as patients, those who could not fulfill their family responsibilities due to caregiving, and those without any support from other family caregivers. The findings of this study are particularly relevant for nurses caring for patients with cancer who have family caregivers. The results indicate that focusing on the family caregivers' QOL-FV may give a better indication of their challenges as well as resources. A QOL-FV perspective may give healthcare professionals an indication of the areas of special importance. On this basis, adequate and tailored interventions to promote QOL-FV and health can be developed.

\section{Conflicting of Interests \\ Disclosure.}

\section{Author Contributions}

Each author participated in the study design, data collection, data analysis, and manuscript preparation, and there are no conflict of interests.

Study design: S.T.K., F.Ö.

Data collection: S.T.K.

Data analysis: S.T.K

Study supervision: F.Ö.

Manuscript writing: S.T.K.

\section{References}

Alptekin S (2010). Characteristics and quality of life analysis of caregivers of cancer patients. Med Oncol, 27, 607-17.

Awadalla AW, Ohoeri JU, Gholoum A, et al (2007). Factors associated with quality of life of outpatients with breast cancer and gynecologic cancer and their family caregivers: A controlled study. BMC Cancer, 19, 102-16.

Babaoğlu E, Öz F (2003). The relationship between psychological and social problems of the spouses who cared for the terminal cancer patients. Turk J Res Dev Nurs, 5, 24-33.

Bektas HA, Ozer ZC (2009). Reliability and validity of the caregiver quality of life index-cancer (CQOLC) scale in Turkish cancer caregivers. J Clin Nurs, 18, 3003-12.

Cameron J, Franche R, Cheung A, Steward D (2002). Lifestyle interference and emotional distress in family caregivers of advanced cancer patients. Cancer, 94, 521-7.

Chang YJ, Kwon YC, Lee WJ, et al (2013). Burdens, needs and satisfaction of terminal cancer patients and their caregivers. Asian Pac J Cancer Prev, 14, 209-16.

Chen JE, Lou WV, Jian H, et al (2018). Objective and subjective financial burden and its associations with health-related quality of life among lung cancer patients. Support Care Cancer, 26, 1265-72

Crespo M, Lopez J, Zarit SH (2005). Depression and anxiety in primary caregivers: A comparative study of caregivers of demented and nondemented older persons. Int J Geriatr Psychiatry, 20, 591-2.

Çivici S, Kutlu R, Çelik HH (2011). Depression status and the factors affecting the quality of life in the relatives of the patients with cancer. Gülhane Med J, 53, 248-53.

Effendy C, Vissers K, Tejawinata S, Dassen MV, Engels Y (2014). Dealing with symptoms and issues of hospitalized patients with cancer in Indonesia: The role of families, nurses, and physicians. Pain Pract, 15, 441-6.

Emanuel E, Fairclough D, Slutsman J, Emanuel L (2000). Understanding economi and other burdens of terminal illness: The experience of patients and their caregivers. Ann Int Med, 132, 451-9.

Ferrell B, Grant M (2005). Quality of life family version (QOL-FV). National Medical Center and Beckman Research Institute.

Ferrell B, Hanson J, Grant M (2013). An overview and evaluation of the oncology family caregiver project: improving quality of life and quality of care for oncology family caregivers. Psychooncology, 22, 1645-52.

Ferrell BR, Grant M, Borneman T, Juarez G, Veer AT (1999). Family caregiving in cancer pain management. $J$ Palliat Med, 2, 185-95.

Gaugler J, Hanna N, Linder J, et al (2005). Cancer caregiving and subjective stress: A multi-site, multidimensional analysis. Psychooncology, 14, 771-85.

Given B, Sherwood PR (2006). Family care for the older person with cancer. Semin Oncol Nurs, 22, 43-50.

Given BA, Given CW, Sherwood PR (2012). Family and caregiver needs over the course of the cancer trajectory. $J$ Support Oncol, 10, 57-64

Görgülü Ü, Akdemir N (2010). Evaluation of fatigue and sleep quality of caregivers advanced stage cancer patients. $J$ Gen Intern Med, 20, 125-32.

Gözüm S, Akçay D (2005). Response to the needs of Turkish chemotherapy patients and their families. Cancer Nurs, 28 , 469-75.

Güllü İ, Zengin N. Kanserle mücadelede ulusal kanser danışma kurulunun rolü. Tuncer M. Editör. Türkiye'de Kanser Kontrolü. Ankara; T.C. Sağlık Bakanlığı Kanserle Savaş Dairesi Başkanlığı, Koza Matbaacılık; 2009;9. 
Hacialioglu N, Özer N, Yilmaz Karabulutlu E, Erdem N, Erci B (2010). The quality of life of family caregivers of cancer patients in the East of Turkey. Eur J Oncol Nurs, 14, 211-7.

Kizılc1 S (1999). Variables affecting the quality of life of cancer patients undergoing chemotherapy and their caregivers. Cumhuriyet Nurs $J, 3,18-26$.

Kim Y, Given BA (2008). Quality of life of family caregivers of cancer survivors: Across the trajectory of the illness. Cancer, 112, 2556-68.

Kim Y, van Ryn M, Jensen RE, et al (2015). Effects of gender and depressive symptoms on quality of life among colorectal and lung cancer patients and their family caregivers. Psychooncology, 24, 95-105.

Kitrungrote L, Cohen MZ (2006). Quality of life of family caregivers of patients with cancer: A literature review. Oncol Nurs Forum, 33, 625-32.

Longo CJ, Fitch M, Deber RB, Williams AP (2006). Financial and family burden associated with cancer treatment in Ontario. Canada. Support Care Cancer, 14, 1077-85.

Mosher CE, Bakas T, Champion VL (2013). Physical health, mental health, and life changes among family caregivers of patients with lung cancer. Oncol NursForum, 40, 53-61.

Mystakidou K, Tsilika E, Parpa E, Galanos A, Vlahos L (2007). Caregivers of advanced cancer patients. Cancer Nurs, $\mathbf{3 0}$, 412-8.

Neyt M, Albrecht J (2006). The long-term evaluation of quality of life. J Psychosoc Oncol, 24, 89-123.

Northouse LL, Katapodi MC, Song L, Zhang L, Mood DW (2010). Interventions with family caregivers of cancer patients: meta-analysis of randomized trials. CA Cancer $J$ Clin, 60, 317-39

Ogce F, Ozkan S, Okcin F, Yaren A, Demiray G (2013). Evaluation of quality of life of breast cancer patient next-of-kin in Turkey. Asian Pac J Cancer Prev, 14, 2771-6.

Okcin F, Karadakovan A (2012). Reliability and validity of the Quality of Life-Family Version (QOL-FV) in Turkish family caregivers of patients with cancer. Asian Pac J Cancer Prev, 13, 4235-40.

Osse B, Vernooij M, Schade E, Grol R (2006). Problems experienced by the informal caregivers of cancer patients and their needs for support. Cancer Nurs, 29, 378-88.

Park B, Kim SY, Shin JY, et al (2013). Prevalence and predictors of anxiety and depression among family caregivers of cancer patients: A nationwide survey of patient-family caregiver dyads in Korea. Support Care Cancer, 21, 2799-807.

Pinkert C, Holtgrawe M, Remmers H (2013). Needs of relatives of breast cancer patients The perspectives of families and nurses. Eur J Oncol Nurs, 17, 81-7.

Scherbring M (2002). Effect of caregiver perception of preparedness on burden in an oncology population. Oncol Nurs Forum, 29, 70-6.

Sercekus P, Besen D, Günüşen N, Edeer A(2014). Experiences of family caregivers of cancer patients receiving chemotherapy. Asian Pac J Cancer Prev, 15, 5063-9.

Skarstein J, Aass N, Fossa S, Skoveland E, Dahl A (2000). Anxiety and depression in cancer patients: Relation between the Hospital Anxiety and Depression Scale and the European Organization for Research and Treatment of Cancer Core Quality of Life Questionnaire. J Psychosomatic Res, 49, $27-34$.

Song JI, Shin DW, Choi JY, et al (2011). Quality of life and mental health in family caregivers of patients with terminal cancer. Support Care Cancer, 19, 1519-26.

Stajduhar KI (2013). Burdens of family caregiving at the end of life. Clin Invest Medi, 36, 121-6.

Sun Young R, Yeonhee P, Su Kyung S, Chung Eun L, Jiyeon L (2015). Caregiving burden and the quality of life of family caregivers of cancer patients: The relationship and correlates. Eur J Oncol Nurs, 19, 376-82.

Tamayo GJ, Broxson A, Munsell M, Cohen MZ (2010). Caring for the caregiver. Oncol Nurs Forum, 37, 50-7

Tsigaroppoulos T, Mazaris E, Chatzidarellis E, et al (2009). Problems faced by relatives caring for cancer patients at home. Int J Nurs Pract, 15, 1-6.

Turkoglu N, Kilic D (2012). Effects of care burdens of caregivers of cancer patients on their quality of life. Asian Pac J Cancer Prev, 13, 4141-5.

Uğur Ö, Fadıloğlu ZÇ (2012). The effect of planned education applied to caregivers of cancer patients on caregiver burdens. Cumhuriyet Nurs J, 3, 53-8.

Visser MR, van Lanschot JJ, van der Velden J, et al (2006). Quality of life in newly diagnosed cancer patients waiting for surgery is seriously impaired. J Surg Oncol, 93, 571-2.

Wadhwa D, Burman D, Swami N, et al (2013). Quality of life and mental health in caregivers of outpatients with advanced cancer. Psychooncology, 22, 403-10.

Yoo J, Lee J, Chang SJ (2008). Family experiences in end-of-life care: A literature review. Asian Nurs Res, 4, 223-34.

Yun Y, Rhee Y, Kang I, et al (2005). Economic burdens and quality of life of family caregivers of cancer patients. Oncology, 68, 107-14.

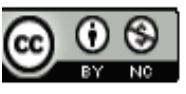

This work is licensed under a Creative Commons AttributionNon Commercial 4.0 International License. 